\title{
Monitoring vegetation cover in Chongqing between 2001 and 2010 using remote sensing data
}

\author{
Qiang Xiao • Jianping Tao • Yang Xiao • Feng Qian
}

Received: 3 November 2016 / Accepted: 27 August 2017 / Published online: 8 September 2017

(C) Springer International Publishing AG 2017

\begin{abstract}
In this study, we applied asymmetric Gaussian function fitting to reconstruct a high-quality MODIS normalized difference vegetation index (NDVI) time series dataset. Following this, we retrieved vegetation cover data from the Chongqing area between 2001 and 2010 using this dataset, applying a dimidiate pixel method. We then used several analytical indices to analyze spatial and temporal changes and trends related to these changes. We determined that a reconstruction of the MODIS NDVI dataset using asymmetric Gaussian fitting in conjunction with a data quality weight coefficient improved data quality and created a foundation for accurate estimations of vegetation cover. We also determined that vegetation cover in the Chongqing area decreased gradually from east to west. During the 10 -year study period, vegetation cover in the Chongqing area generally increased, changing from low to high coverage. This increase in vegetation cover was mainly
\end{abstract}

Q. Xiao · J. Tao $(\bowtie) \cdot$ F. Qian

Key Laboratory of Eco-environments in Three Gorges Reservoir Region (Ministry of Education), Chongqing Key Laboratory of Plant Ecology, and Resources Research in Three Gorges Reservoir Region, School of Life Sciences, Southwest University,

Chongqing 400715, China

e-mail: taojianping@163.com

Q. Xiao

Chongqing College of Arts and Sciences, Chongqing 402160, China

Y. Xiao

State Key Laboratory of Urban and Regional Ecology, Research Center for Eco-Environmental Sciences, Chinese Academy of Sciences, Beijing 100085, China the result of ecological protection policies and improving climate conditions. We also found that changes in vegetation cover were mainly the result of urban construction and afforestation initiatives, but vegetation cover improved overall.

Keywords TIMESAT - Dimidiate pixel model . Vegetation cover $\cdot$ Dynamic change analysis

\section{Introduction}

Terrestrial vegetation is a critical link in mass and energy exchanges between the soil, water, and air, and it plays important roles in energy exchanges for land surfaces, hydrological cycles, and biogeochemical cycles (Turrion et al. 2007). Generally, changes in the spatial pattern of vegetation types reflect the response of vegetation structure to changes in hydrothermal conditions and the long-term effects of human activities (Comiti et al. 2011). Once changes to vegetation structures occur, the phenology, cover, and production of vegetation will inevitably change, leading to feedbacks that cause the vegetation structure to change in response to the ever-changing environment. Because a region's vegetation directly reflects its climatic, hydrological, and soil conditions, vegetation is an important indicator of environmental change.

Vegetation cover refers to the percentage of the vertical projected area of vegetation (including leaves, stems, and branches) within the overall statistical area. It is an important input parameter by which to monitor global and regional climate models and water and soil 
losses as well as to evaluate land desertification and construct distributed hydrological models (Miao et al. 2016a). In other words, it is the basic data that describes eco-environmental systems. Therefore, the quantitative evaluation of regional vegetation coverage and the analysis of the status of vegetation cover are both of great practical significance in understanding variational trends in aboveground vegetation, analyzing and evaluating regional land resource management, and decision-making procedures in environmental protection policies (Lanfredi et al. 2004; Okin 2007). Vegetation cover is also an important input parameter in global and regional climate models, in soil and water erosion monitoring, in the evaluation of desertification, and in distributed hydrological models, as well as important basic data used to describe ecosystems (Okin et al. 2013).

Currently, remote sensing is primarily used to estimate vegetation cover over large areas, and it is often combined with measurements obtained from surface observations (ground-truth data) using a variety of methods (Kong et al. 2015). Traditional ground-truth measurements are more accurate for measuring vegetation cover in small areas, but these measurements are difficult to apply to large areas due to their excessive time and cost constraints. Fortunately, advances in remote sensing technology have made it possible to estimate vegetation cover from remote sensing satellite images with increasing accuracy. Furthermore, the selection of appropriate data and its conversion into appropriate vegetation indices are critical to the successful estimation of vegetation cover (Barati et al. 2011). Vegetation indices are based on linear or nonlinear combinations of reflectance values, which are obtained for various ranges of wavelengths. Among these indices, the normalized difference vegetation index (NDVI) is frequently used, because it strongly correlates to vegetation cover, it has exceptional temporal resolution, and it is adaptable to a wide range of surface conditions (Xiao et al. 2015).

Researchers have investigated the relationships between changes in vegetation cover and climate (e.g., Anupama et al. 2014). During the past 20 years, vegetation growth has been increasingly affected by global warming, particularly at high northern latitudes (Dubovyk et al. 2013). Chinese scholars have also studied vegetation cover extensively, and they have demonstrated that the interannual fluctuation in spring NDVI in the Northern Hemisphere is associated with large-scale meteorological systems ( $\mathrm{Li}$ et al. 2013). In China, vegetation growth has strengthened since 1990; compared to coverage in the early 1980 s, vegetation cover had increased by $3.5 \%$ by the end of the 1990s, and the annual average NDVI had increased by $7.4 \%$. These increases in vegetation cover have mostly occurred in western and northwestern China, particularly in the Xinjiang Uyghur Autonomous Region, where precipitation has also increased. Furthermore, NDVI is closely associated with a region's temperature, and seasonal variation is strongly associated with patterns in seasonal rainfall (Cao et al. 2010).

Although NDVI is strongly associated with vegetation cover, the conversion between the two values depends on vegetation characteristics as well as other factors, such as the topography and soil that affect the characteristics of signals captured by satellite images (Chauhan and Ganguly 2011). To date, NDVI has generally been converted into vegetation cover by empirical models that emphasize the relationship between the two parameters (Qu et al. 2014). Particularly, for sensors with low spatial resolution, mixed pixel methods are often used, in which the vegetation cover within each pixel is estimated by applying certain algorithms to distinguish between vegetation information and non-vegetation information (Miao et al. 2016b). Empirical models are most useful over short time periods, and this is because the changes in vegetation used to calibrate the model can lead to changes in the predictive ability of the model. Mixed pixel methods have an advantage over empirical methods, because they are less dependent on empirical studies and can potentially establish a time-invariant relationship between NDVI and vegetation cover (Zhang Junze et al. 2016).

In this study, we selected the Chongqing area in southwestern China as a case study to apply remote sensing data in which to analyze changes in vegetation cover, the spatial characteristics of factors that drive changes in vegetation cover, and the dynamics of vegetation cover. This region has undergone rapid economic development and urbanization, including large-scale ecological restoration projects. It is therefore important for regional planners to understand the net effects of these changes and identify regions where additional ecological restoration measures may be necessary.

\section{Study area and data sources}

Study area

The study area (Chongqing City and its surrounding area) is located between $105^{\circ} 11^{\prime} \mathrm{E}$ and $110^{\circ} 11^{\prime} \mathrm{E}$ and between 
$28^{\circ} 10^{\prime} \mathrm{N}$ and $32^{\circ} 13^{\prime} \mathrm{N}$ (Fig. 1). It includes the lower section of the upper reaches of the Yangtze River, and it covers a total area of $82,400 \mathrm{~km}^{2}$, with a total population of 30.1 million. The topography of the region is complex, with lower elevations in the west and higher elevations in the east. The region has a subtropical monsoon climate, and it experiences humid conditions for most of the year. The annual mean temperature ranges from 17 to $19{ }^{\circ} \mathrm{C}$, with mean minimum and maximum temperatures of 4 to $8{ }^{\circ} \mathrm{C}$ in January and 26 to $29^{\circ} \mathrm{C}$ in July, respectively. The mean annual precipitation is approximately $1100 \mathrm{~mm}$. Rainfall is variable in both amount and timing, but approximately $85 \%$ of the annual rainfall occurs during the summer months (from June to September).

Chongqing is an important ecological and biodiversity shelter zone in the Yangtze River Basin and has been designated a national strategic conservation area for water resources. The area's land use and land cover have changed significantly due to rapid population and economic growth. Large-scale ecological restoration projects, such as the Conversion of Farmland to Forest
Program and the Natural Forests Protection Program, have led to an increase in vegetation cover. On the other hand, its increasing population has led to significant vegetation degradation. For these reasons, it is important to maintain a stable or improving ecological environment in this region that is capable of sustaining agricultural and socioeconomic development. To support such goals, it is necessary to comprehensively analyze the recent spatial and temporal changes in Chongqing vegetation cover and identify the drivers of these changes.

The region of the study area has undergone rapid population growth and economic development, accompanied by urban expansion, excessive cultivation, and forest harvesting (Lan et al. 2016). Rivers are being overburdened by growing urban domestic sewage, industrial waste, and agricultural pesticides and fertilizers, causing serious water pollution and degradation of the ecological environment (Wu et al. 2016). Moreover, due to a combination of natural factors and recent human activities, soil erosion is becoming increasingly severe in certain sections of the study area.

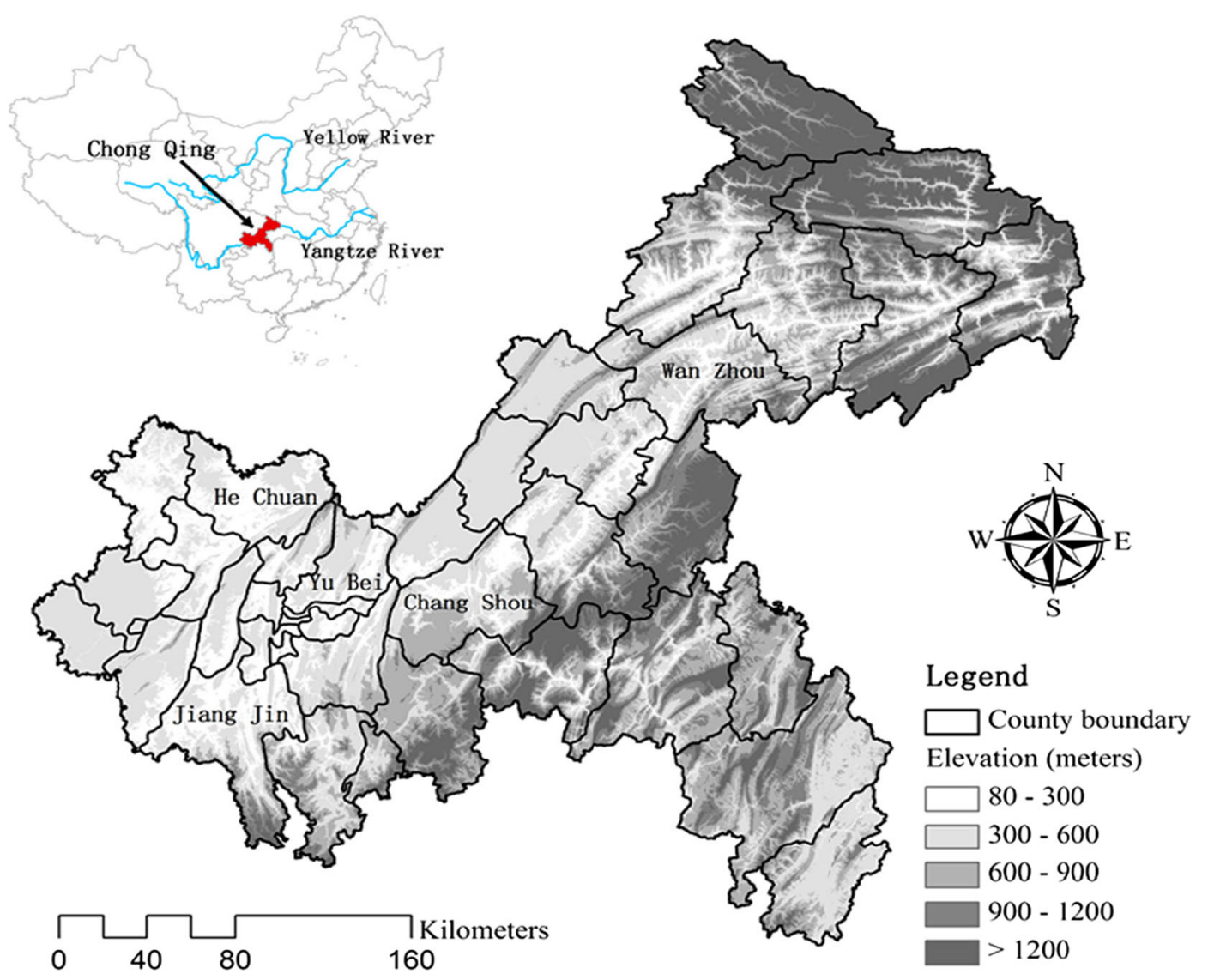

Fig. 1 The location of the study area 
Data sources

This study used Terra (EOS) satellite MOD13Q1 V005 MODIS vegetation product remote sensing data. We obtained composite 16-day NDVI time series data based on the maximum-value compositing (MVC) method and available quality control data. The satellite product was geometrically and atmospherically corrected. The time series dataset comprised of 230 images taken between 2001 and 2010 by NASA's Land Process Distributed Active Archive Center (LA DAAC; https://pdaac.usgs. gov/). We then extracted the data pixel reliability dataset to describe the quality of the NDVI data (Table 1).

Other data included the MODIS land cover type product (MCD12Q1) from 2001 to 2010 with a spatial resolution of $500 \mathrm{~m}$ and land use and land cover type data with a resolution of $250 \mathrm{~m}$ (converted from $30 \mathrm{~m}$ ) based on the visual interpretation of Landsat $5 \mathrm{TM}$ images from 2001, 2005, to 2010.

We obtained soil data from the second national soil survey of China. This information included soil types, their particle-size distribution, soil organic matter content, and soil depth at a scale of 1:1,000,000. This study used precise diachronic classifications of the study area as a reference for object-oriented image classification based on a $30-\mathrm{m}$ resolution Landsat images from the beginning of the dry season (i.e., the time of maximum vegetation cover) between 2001 and 2010 .

\section{MODIS NDVI time series analysis}

To reconstruct a reliable NDVI time series dataset, it was necessary to further reduce residual noise following the reliability check procedure (as shown in Table 1), such as false high and low values. To do so, we applied the mixed pixel model method, which has been widely used
(Jönsson and Eklundh 2002). TIMESAT software (http://www.nateko.lu.se/TIMESAT/timesat.asp) provides Savitzky-Golay filtering, asymmetric Gaussian fitting, and double-logistic fitting to reconstruct time series datasets and extract phenological information on vegetation growth (Jönsson and Eklundh 2002).

We adopted the asymmetric Gaussian fitting method (Pulido-Fernández et al. 2013; Bauer and Strauss 2014), because it accounts for the upper envelope of the NDVI curve and preserves the fidelity of the original high-quality point values (Cao et al. 2011). The asymmetric Gaussian and double-logistic methods function in a similar way to preserve the fidelity of the original high-quality NDVI samples, and their fitted NDVI series are better than those produced by Savitzky-Golay filtering, with the exception of the peak of the growing season. Of the three algorithms, the asymmetric Gaussian fitting method produces results that best approximate the upper envelope of the NDVI curve (Cao 2011).

Parameter setting is a critical part in the smoothing of original NDVI time series. The key parameters and the values we selected for these parameters are the effective range (from -0.1 to 1.00 ) and the weight value of the original NDVI (Table 1). In this study, weight was set to 0.5 to adjust to farmland cover types, while other weights were set to 1 . We then resampled NDVI data as raster data with a spatial resolution of $250 \mathrm{~m}$, and we expressed the digital number (DN) value of new pixels as vegetation cover by means of algebraic operations (Wilson et al. 2013). We overlaid these results with current vegetation cover data inverted from MODIS NDVI data to conduct a consistency check.

The monthly NDVI data represent the 32-day NDVI data that we composited using the MVC method from the 16-day NDVI data that were fitted using the asymmetric Gaussian fitting method (Setiawan et al. 2014). In
Table 1 Description of pixel digital number (DN) values for the "data pixel reliability dataset" in the MOD13Q1 V005 product

\begin{tabular}{clll}
\hline Pixel value & Meaning & Description & Selected weight \\
\hline-1 & Filling value & Pixel has not been processed & 0 \\
0 & Good quality & High reliability & 1.0 \\
1 & Relatively goodquality & Relatively reliable & 0.8 \\
2 & Covered by ice and snow & Affected by noise from ice & 0.2 \\
& & and snow cover and was \\
& thus deemedsubsequently & \\
& & unreliable \\
3 & Covered by clouds & The target was covered by \\
& & clouds and was thus deemed \\
& & subsequently unreliable \\
& &
\end{tabular}


this study, we focused on comparing and analyzing the fitting of the reconstructed NDVI time series to the upper envelope curve of the original NDVI values and the fidelity of preservation of the original high-quality NDVI point values. Figure 2 shows that noise either decreased or was eliminated, thereby greatly improving the data quality compared to the original, given that the NDVI values for pixels with cloud or ice noise (pixel values 3 and 2) were reconstructed by TIMESAT (Bargiel et al. 2013).

\section{Dimidiate pixel model}

The dimidiate pixel model assumes that the ground surface represented by a pixel comprises a mixture of vegetation cover and non-vegetation cover areas (Jing et al. 2011). The spectral information observed by the remote sensor represents a linearly weighted synthesis of these two components, with the weight of each component representing the proportion of the pixel area accounted for by each component. Thus, vegetation cover can be represented by the weight of the vegetation (Zhang et al. 2009).

For the dimidiate pixel model, the information $(S)$ observed by the remote sensor can be expressed as the combination of $S_{\mathrm{v}}$ contributed by vegetation and $S_{\mathrm{s}}$ contributed by bare soil. $S$ can be linearly decomposed into $S_{\mathrm{v}}$ and $S_{\mathrm{s}}$ as follows:

$S=S_{\mathrm{v}}+S_{\mathrm{s}}$

For mixed pixels that contain both soil and vegetation, the proportion of vegetation cover area in the pixel is represented by $f_{\mathrm{c}}$ (vegetation cover), and the proportion of soil cover area is represented by $1-f_{\mathrm{c}}$. Pure pixels that are fully covered by vegetation are represented by $S_{\mathrm{veg}}$, which is calculated as follows:

$S_{\mathrm{v}}=f_{\mathrm{c}} S_{\mathrm{veg}}$

Similarly, pure pixels that are fully covered by soil are represented by $S_{\text {soil }}$, which is calculated as follows:

$S_{\mathrm{s}}=\left(1-f_{\mathrm{c}}\right) S_{\text {soil }}$

Equations (2) and (3) can be substituted into Eq. (1) to obtain the following:

$S=f_{\mathrm{c}} S_{\mathrm{veg}}\left(1-f_{\mathrm{c}}\right) S_{\text {soil }}$

Equation (4) shows how $S$ is linearly decomposed into $S_{\text {veg }}$ and $S_{\text {soil }}$, whose weights $\left(f_{\mathrm{c}}\right.$ and $\left.1-f_{\mathrm{c}}\right)$ represent the respective proportions of the pixel area for which they account. This analysis assumes that a pixel can only contain vegetation or soil. To determine vegetation cover, Eq. (4) can be resolved for $f_{\mathrm{c}}$ as follows:

$f_{\mathrm{c}}=\left(S-S_{\text {soil }}\right) /\left(S_{\mathrm{veg}}-S_{\text {soil }}\right)$

The remote sensing information for each pixel can therefore be used to estimate the vegetation cover in each pixel using Eq. (5). Based on the dimidiate pixel model, the NDVI value of a pixel can be expressed as a combination of $\mathrm{NDVI}_{\mathrm{veg}}$, which is contributed by green vegetation, and $\mathrm{NDVI}_{\text {soil, }}$ which is contributed by bare soil. The NDVI value of a pixel can also be substituted into Eq. (5), because it also meets the conditions of Eq. (4):

$f_{\mathrm{c}}=\left(N D V I-N D V I_{\text {soil }}\right) /\left(N D V I_{\mathrm{veg}}-N D V I_{\text {soil }}\right)$

where $\mathrm{NDVI}_{\text {soil }}$ refers to the NDVI value $\left(\mathrm{NDVI}_{\text {min }}\right)$ of areas that are fully covered by bare soil or non-vegetation,
Fig. 2 Comparison of the reconstructed NDVI time series based on an asymmetric Gaussian function with unprocessed NDVI time series

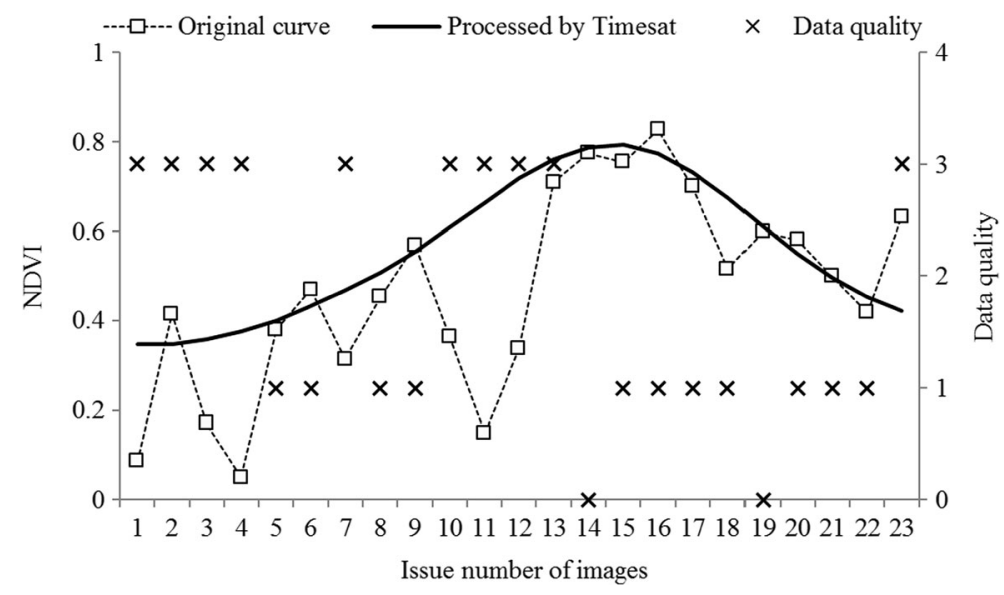


and $\mathrm{NDVI}_{\text {veg }}$ refers to the NDVI value of a pixel fully covered by vegetation $\left(\mathrm{NDVI}_{\max }\right)$ (Kyle and Duncan 2012). Value selections are determined by image scale (i.e., pixel dimensions) and image quality, because extreme values of NDVI may not always be $\mathrm{NDVI}_{\max }$ or $\mathrm{NDVI}_{\text {min }}$ due to the inevitable presence of image noise. When actual measured values are not available, $\mathrm{NDVI}_{\max }$ and $\mathrm{NDVI}_{\text {min }}$ can account for the maximum and minimum values in a confidence interval, respectively, which describe the image data (Zhou et al. 2009). In this context, $\mathrm{NDVI}_{\max }$ represents the NDVI value that corresponds to the $95 \%$ quantile of the probability distribution of NDVI, which typically corresponds to forest vegetation types; conversely, $\mathrm{NDVI}_{\min }$ represents the NDVI value that corresponds to the $5 \%$ lower quantile of the probability distribution of NDVI, which typically corresponds to bare land and sparse vegetation types. For the purpose of dynamically monitoring changes in vegetation cover, we estimated the annual average vegetation cover from 2001 to 2010 and used this information to analyze annual changes in vegetation cover.

Trend analysis for changes in vegetation cover

We used a method that detects changes in slope of the NDVI curve to detect trends in vegetation cover in each pixel from 2001 to 2010 (Anderson et al. 2005). Vegetation cover shows a decreasing trend in the area where the slope has a negative value, while vegetation cover shows an increasing trend when the slope has a positive value. The higher the absolute number of a slope, the greater the increasing scale of vegetation cover will be.

$X=\frac{n \times \sum_{i=1}^{n} i \times f_{c i}-\left(\sum_{i=1}^{n} i\right)\left(\sum_{i=1}^{n} f_{c i}\right)}{n \times \sum_{i=1}^{n} i^{2}-\left(\sum_{i=1}^{n} i\right)^{2}}$

where $X$ refers to the slope of the curve, $n$ refers to the number of years during the study period, and $f_{\mathrm{c} i}$ represents the vegetation cover in the $i^{\text {th }}$ year. A positive slope indicates an increase in vegetation cover, whereas a negative slope indicates a decrease in vegetation cover (Ivits et al. 2009).

If the value of a slope has a significance level of 0.05 $(P<0.05)$, a decrease or increase in vegetation cover is considered significant; if a value of a slope has a significance level of $0.01(P<0.01)$, a decrease or increase in vegetation cover is considered extremely significant. The calculated probability $(P)$ was used to express the evaluation standard of vegetation cover change of each pixel from 2001 to 2010 (Table 2). Additionally, we used
Table 2 Significance of the changes in vegetation cover

\begin{tabular}{lll}
\hline Trend & $X$ value range & Significance level \\
\hline Very significant decrease & $X<0$ & $P<0.01$ \\
Significant decrease & $X<0$ & $0.01<P<0.05$ \\
Very significant increase & $X>0$ & $P<0.01$ \\
Significant increase & $X>0$ & $0.01<P<0.05$ \\
No significant changes & & $P \geq 0.05$ \\
\hline
\end{tabular}

the trend significance test ( $P$ value) to determine significant changes in area. The smaller the $P$ value, the greater the trend in significance will be (Jiapaer et al. 2011).

In this study, we classified land use and cover types using Landsat 5 TM images of the study area, and we used the resulting classification to evaluate inversion accuracy of NDVI in estimating vegetation cover during corresponding periods. First, we grouped the original land cover types into two categories: vegetation (forests, shrubs, meadows, and active or fallow farmland) and non-vegetation (all other land cover types). We then resampled the MODIS images to a spatial resolution of $25 \mathrm{~m}$ to meet the accuracy requirements for this type of analysis (Ouyang et al. 2010). Three common algorithms were used to resample pixels: the nearest neighbor, bilinear interpolation, and cubic convolution interpolation algorithms. It is important to note that resampling does not change the accuracy of any of the three algorithms used. For example, pixel A represented land type A before resampling and represented land type A after resampling. In this study, a resolution of $250 \mathrm{~m}$ was converted to $25 \mathrm{~m}$ without any changes in accuracy (Wing et al. 2012).

\section{Results and analysis}

Spatial distribution of fractional vegetation cover

Our results found high fractional vegetation cover (FVC) in the eastern section of the study area and low fractional vegetation cover in the western section. The areas with high fractional vegetation cover $(>70 \%)$ were mainly mountainous areas in central, southeastern, and northeastern Chongqing, whereas areas with low fractional vegetation cover $(<70 \%)$ were mainly plains in western Chongqing, which has undergone rapid urbanization (Fig. 3).

Since 2000, national ecological restoration policies, such as the Grain-to-Green Program and the Natural Forests Protection Program, have greatly increased 

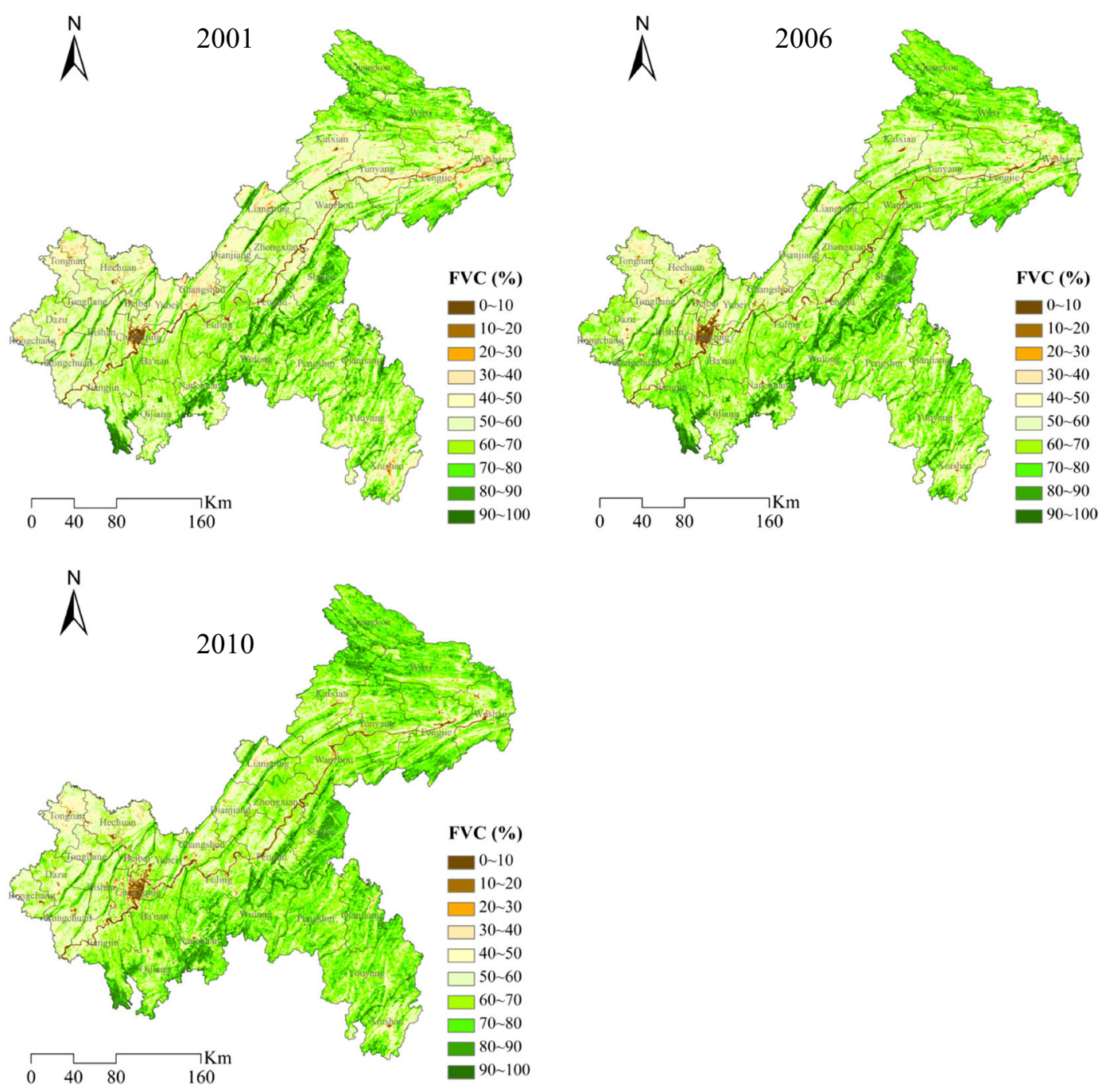

Fig. 3 Changes in fractional vegetation cover (FVC) in the Chongqing area from 2001 to 2010

vegetation recovery in the Chongqing area. By 2008, for example, greater than $1.1 \times 10^{6}$ ha of farmland was converted to forests. By 2011, forest area had increased from $1.80 \times 10^{6}$ ha to $3.05 \times 10^{6}$ ha, which is an increase of $69.4 \%$.

Temporal distribution of vegetation cover

During the study period, vegetation cover generally increased in the Chongqing area. Annual average vegetation cover reached its maximum in 2009 (64.3\%). Figure 4 shows the changes in vegetation cover from 2001 to 2010. Areas with a vegetation cover $\geq 60 \%$ increased significantly during the study period, while areas with a vegetation cover from 70 to $80 \%$ showed the greatest increase, that is, from $11,968.13 \mathrm{~km}^{2}$ in 2001 to $20,491.06 \mathrm{~km}^{2}$ in 2010 , which is an increase of $71.2 \%$.

On the other hand, areas with $<60 \%$ vegetation cover decreased significantly throughout the study period. Areas with a vegetation cover from 40 to $50 \%$ showed the greatest decrease, from $13,327.69 \mathrm{~km}^{2}$ in 2001 to $4901.19 \mathrm{~km}^{2}$ in 2010 , which is a decrease of $63.2 \%$. In the Chongqing municipality itself, the transformation from low vegetation cover $(<60 \%)$ to high vegetation cover $(>60 \%)$ illustrated the propitious development of the eco-environment in the research area and the active eco-environmental protection policies in the northeast of Chongqing region. Our analysis found that vegetation cover was largely influenced by the current ecological construction policies enacted by the government. 
Fig. 4 Changes in vegetation cover in 10 categories from 2001 to 2010

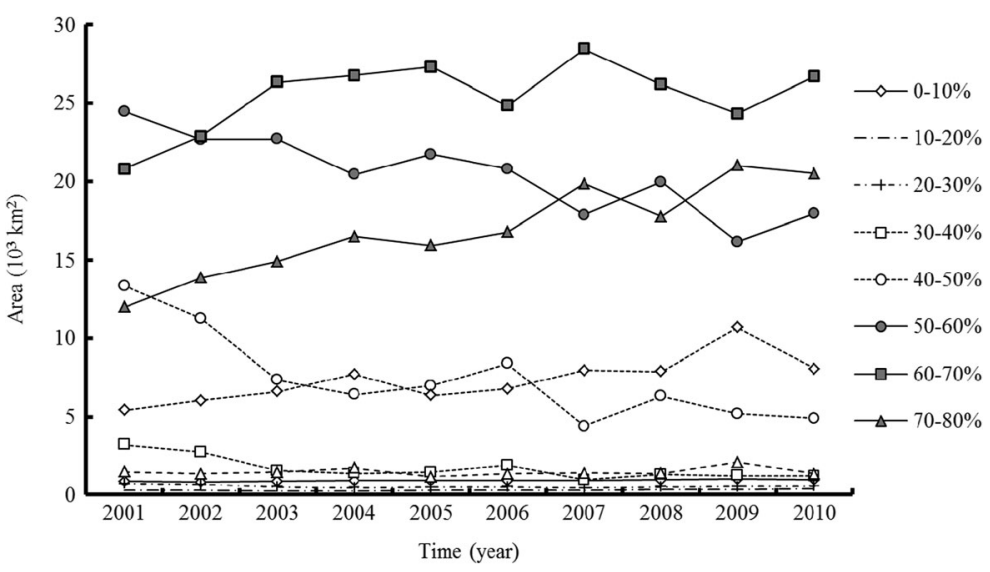

Trends in vegetation cover change

Although vegetation cover in the Chongqing area has undergone fluctuation, it generally increased between 2001 and 2010, especially in the southeastern and northeastern sections of the Chongqing area. However, vegetation cover declined by 59.6 and $61.6 \%$ in 2001 and 2006 , respectively, due to severe droughts in southwestern Chongqing. In 2001, the annual average vegetation cover in Chongqing was $60.3 \%$, increasing to $63.9 \%$ in 2007. In 2009, vegetation cover in Chongqing reached $65.8 \%$, but it decreased to $64.9 \%$ in 2010 . We used linear regression to determine vegetation cover trends in Chongqing during three different periods (from 2001 to 2005 , from 2005 to 2010 , and from 2001 to 2010).

Figure 5 shows that vegetation cover increased significantly in central Chongqing between 2001 and 2005 and in the southeastern mountainous area, but it decreased significantly mainly in the western and northeastern urbanized areas. From 2005 to 2010, it increased significantly mainly in the southern and northeastern mountainous areas, but it decreased significantly mainly in the urbanized areas of central Chongqing. From 2001 to 2010, it increased significantly in mountainous areas and in hilly areas of Kai County, Yunyang County, Fengjie County, and Wushan County, but it decreased in the southeastern, central, and western plain areas. Vegetation cover also decreased significantly in plain areas in Fengdu County, Fuling District, Changshou District, and Beibei District. By examining land use and cover types determined by the interpretation of original remote sensing images and field investigations, we found that urban construction, revegetation, and climatic change, all affected changes in vegetation cover.
Accuracy of vegetation cover values

As shown in the "Data sources" subsection, resampled data was overlain with current vegetation cover data, which was inverted from MODIS NDVI data, to conduct a consistency check. For the study area as a whole, there was a statistically significant correlation between the two datasets $\left(R^{2}=0.9581 ; P<0.001\right)$. On a pixel level, we found a strong and significant linear relationship $\left(R^{2}=0.815 ; n=9823 ; P<0.001\right)$ between the two datasets, and the differences between the values were within \pm 0.1 . Additionally, correlations were stronger in conjunction with precipitation during the current growing season; the strongest correlation $(r=0.724 ; P<0.05)$ was observed in precipitation from July of the previous year to July of the current growing season. These results indicated that the inversion accuracy $(76 \%)$ of vegetation cover based on the MODIS NDVI data was appropriate.

\section{Discussion}

Analysis of factors contributing to vegetation cover changes. Dynamic changes and spatial patterns in vegetation cover are important indicators that support research associated with land management and environmental changes. Many vegetation indices have been developed to convert remote sensing image data into information on vegetation cover for a range of study objectives (Omuto et al. 2010; Eckert and Engesser 2013). Among these indices, NDVI is widely recognized as an effective index to use to monitor regional and global vegetation changes, because it can compensate for changes caused by differences in lighting conditions, soil color, slope, and observational orientation. 

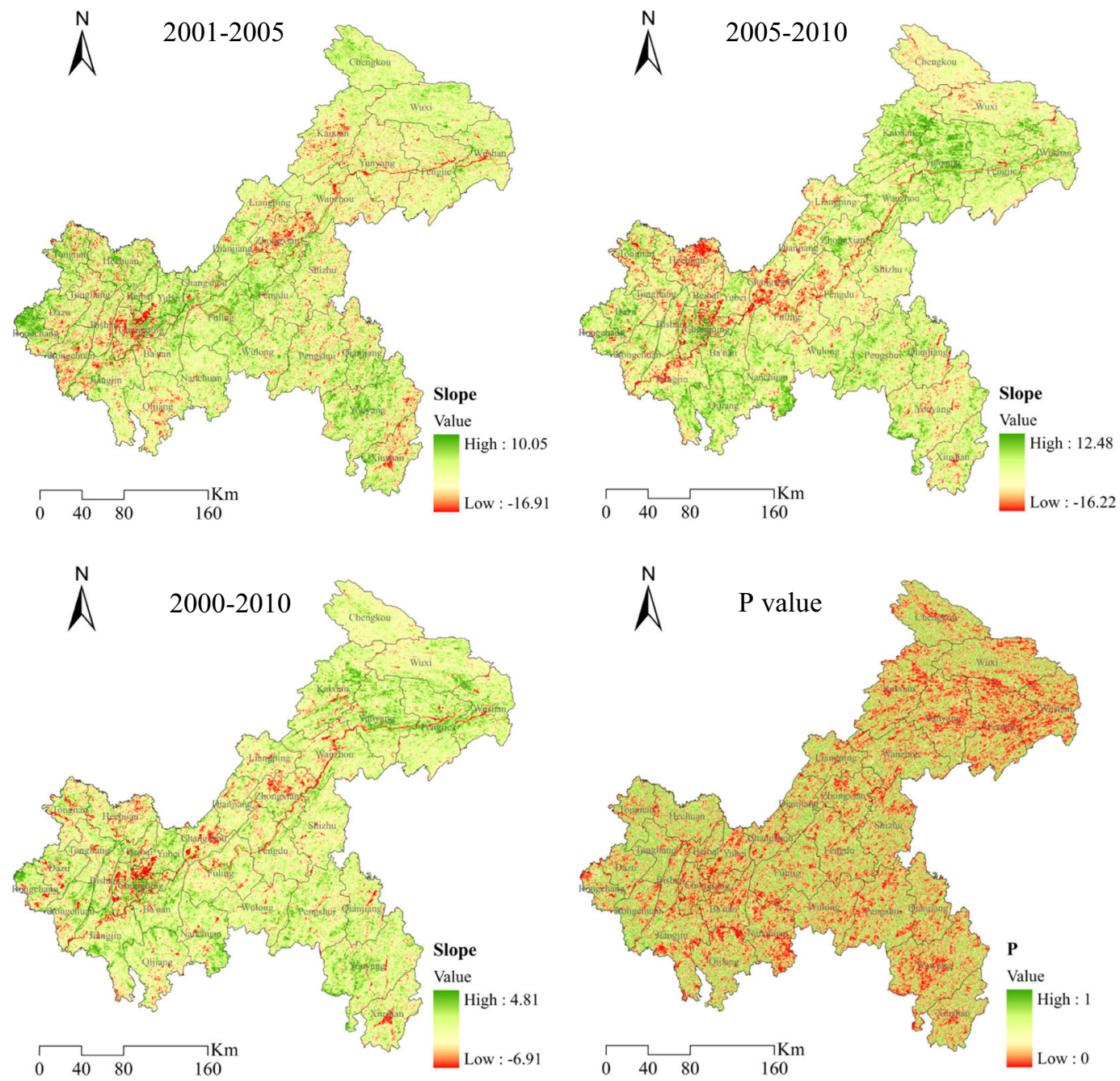

Fig. 5 Slope of the linear regression change trend in vegetation cover in Chongqing during. $P$ value means significance of change

Fig. 6 Yearly and monthly temporal variations in fractional vegetation cover (FVC) and precipitation

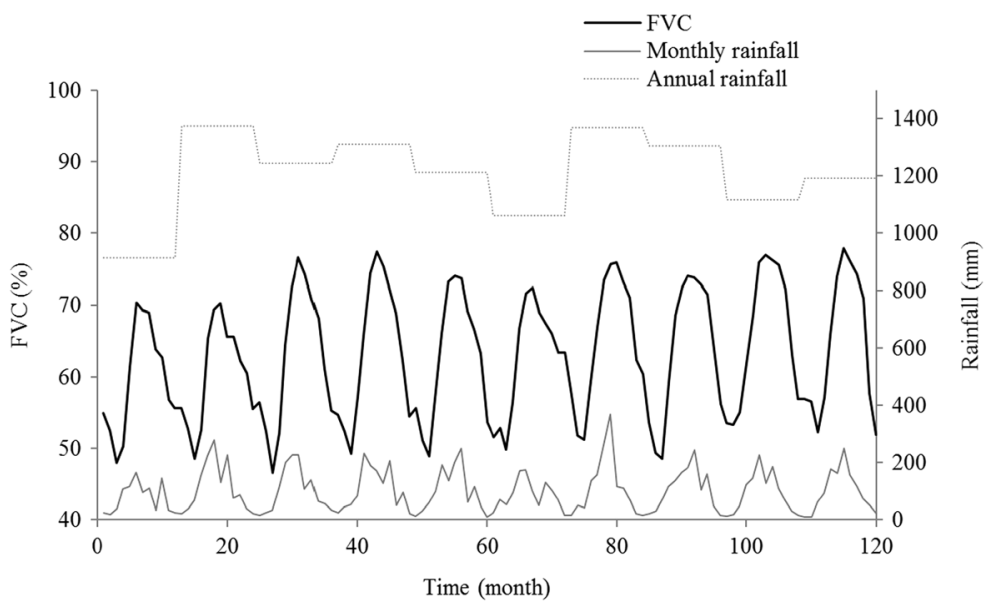


Table 3 Correlations (Pearson's $r$ ) between vegetation cover and precipitation during different time periods

\begin{tabular}{llllllll}
\hline & $\begin{array}{l}\text { April to } \\
\text { July }\end{array}$ & $\begin{array}{l}\text { May to } \\
\text { July }\end{array}$ & $\begin{array}{l}\text { June to } \\
\text { July }\end{array}$ & $\begin{array}{l}\text { Previous July } \\
\text { to current July }\end{array}$ & $\begin{array}{l}\text { Previous August } \\
\text { to current July }\end{array}$ & $\begin{array}{l}\text { Previous September } \\
\text { to current July }\end{array}$ & $\begin{array}{l}\text { Previous October } \\
\text { to current July }\end{array}$ \\
\hline Correlation coefficient $\left(R^{2}\right)$ & 0.639 & 0.653 & 0.698 & 0.724 & 0.536 & 0.396 & 0.203 \\
\hline
\end{tabular}

Among these indices, NDVI is widely recognized as an effective index to monitor regional and global vegetation changes, because it can compensate for changes caused by differences in lighting conditions, soil color, slope, and observational orientation. Accordingly, NDVI has been widely applied in resource and environmental studies.

Changes in climate conditions directly affect vegetation growth, distribution, and phenological development. In this study, we only considered precipitation effects due to a lack of spatially explicit temperature data. Figure 6 shows that precipitation and vegetation cover followed the same pattern in annual changes from 2001 to 2010. However, changes in vegetation cover were inconsistent with changes in annual precipitation over a number of years (Soepboer et al. 2010; Cao et al. 2011). This indicated that during these years, other factors affected vegetation cover more strongly than precipitation, such as human activities (e.g., agricultural reclamation, overgrazing, irrigation, and afforestation) and environmental factors, such as temperature and effective solar radiation.

Because hysteresis often exists between plant growth and climatic changes, and the impact of precipitation differs between vegetation growth stages, we calculated correlations between precipitation from 2001 to 2010 and mean vegetation cover during corresponding years (Table 3) to reveal potential hysteresis. We found that precipitation from the end of the previous growing season to various months during the current growing season had little effect on vegetation cover, and this was potentially because vegetation cover in the Chongqing area reaches its maximum in July each year (Cao et al. 2016).

Figure 7 shows the spatial distribution of correlations between average annual vegetation cover and precipitation for the maximum temporal duration. Vegetation cover was significantly positively correlated to precipitation during this period in most areas of Chongqing, while a negative correlation was mostly observed in urbanized areas. We
Fig. 7 Correlation coefficient (Pearson's $r$ ) between precipitation (from the previous July to the current July) and the annual mean vegetation cover from 2001 to 2010

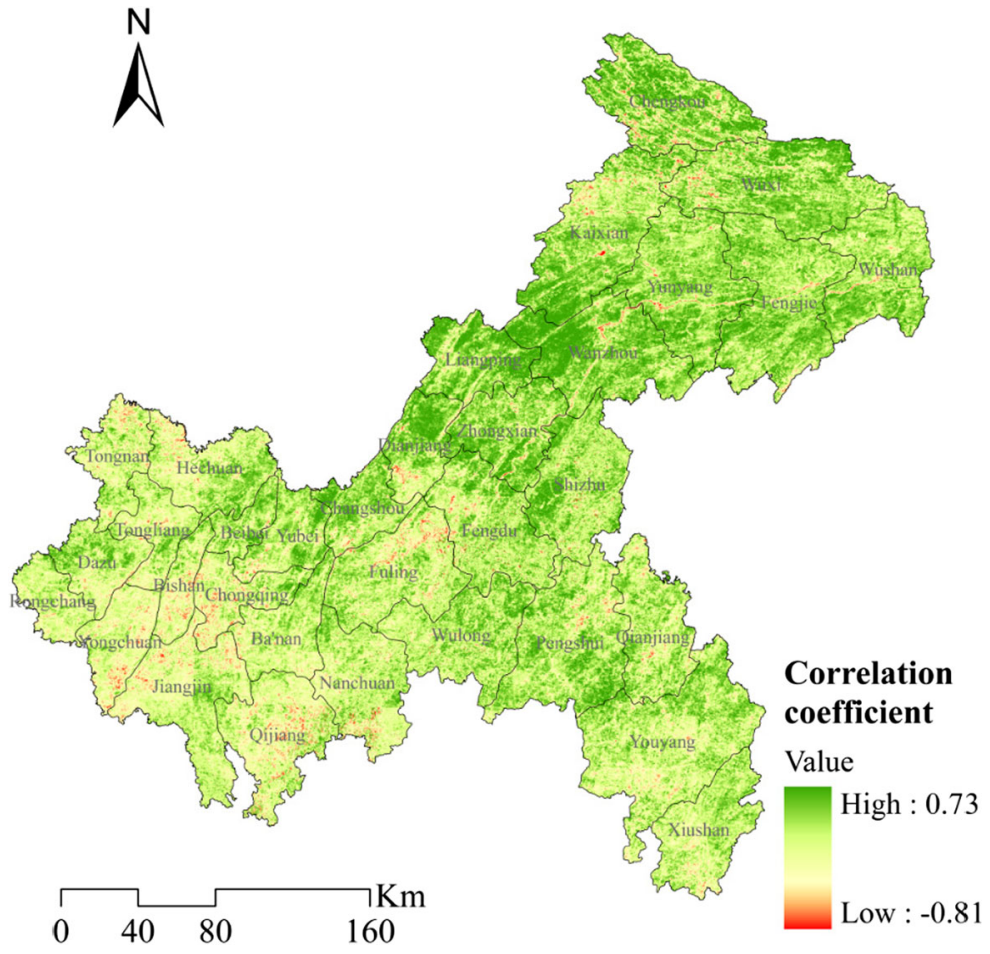


mainly found positive correlations in northeastern Chongqing, such as Chengkou County, Wanzhou District, Liangping County, and Dianjiang County. The strong positive correlations in most areas suggested that precipitation was an important factor that affected vegetation cover in the study area, and it should therefore be taken into account when revegetation planning initiatives are under review. Negative correlations were mostly found in western areas of Chongqing, such as the central downtown area, Yongchuan District, Jiangjin District, and Qijiang District, where main land use types are urban or irrigated farmland. Precipitation did not play an important role in determining vegetation cover in these areas, because there is little vegetation, and because vegetation is supported by irrigation rather than rainfall.

Compared to western Chongqing, correlation coefficients were stronger in the northeast. Because of the mountainous topography and less intensive human activities, vegetation coverage in northeastern Chongqing is mainly influenced by natural factors, such as precipitation. On the other hand, vegetation coverage in western Chongqing is mainly influenced by human activities, because the topography is mainly plains, and the main land cover types are artificial (Goirán et al. 2012; Gao et al. 2011).

\section{Conclusions}

In this study, we reconstructed vegetation cover from MODIS NDVI data by means of an asymmetric Gaussian fitting method implemented using the TIMESAT software. We used this approach to estimate vegetation cover in the Chongqing area from 2001 to 2010 and to analyze its spatial distribution and temporal trends as well as underlying driving factors.

(1) We found that in the Chongqing area, vegetation cover gradually decreased in an east to west direction. However, vegetation cover generally showed an increasing trend in most areas, and areas that had low vegetation cover $(<60 \%)$ at the start of the study period often changed to areas with high vegetation cover $(>60 \%)$ by the end of the study period. Our findings showed that increases in vegetation cover have been mainly due to national ecological restoration policies, such as the Conversion of Farmland to Forest Program and the Natural Forests Protection Program.
(2) Vegetation cover mostly increased in mountainous regions and hilly areas, but mostly decreased in plain areas. By comparing NDVI results with Landsat TM data, we found that urban construction and afforestation were the major causes of these observed changes in vegetation cover.

(3) We found that the methods used in this study could help future studies better determine changes in vegetation cover and regional planners to understand the effects of these changes and identify regions where additional ecological restoration measures may be necessary.

Acknowledgments This study was supported by the National Foundation of Natural Sciences of China (No. 31570612).We would like to thank Brian DOONAN for his help in writing this paper as well as to the journal editors and anonymous reviewers for their comments on an earlier version of this manuscript.

\section{References}

Anderson, A. B., Wang, G., Fang, S., Gertner, G. Z., Güneralp, B., \& Jones, D. (2005). Assessing and predicting changes in vegetation cover associated with military land use activities using field monitoring data at Fort Hood, Texas. Journal of Terramechanics, 42, 207-229.

Anupama, K., Prasad, S., \& Reddy, C. S. (2014). Vegetation, land cover and land use changes of the last 200 years in the Eastern Ghats (southern India) inferred from pollen analysis of sediments from a rain-fed tank and remote sensing. Quaternary International, 325, 93-104.

Barati, S., Rayegani, B., Saati, M., Sharifi, A., \& Nasri, M. (2011). Comparison the accuracies of different spectral indices for estimation of vegetation cover fraction in sparse vegetated areas. Egyptian Journal of Remote Sensing and Space Science, 14, 49-56.

Bargiel, D., Herrmann, S., \& Jadczyszyn, J. (2013). Using highresolution radar images to determine vegetation cover for soil erosion assessments. Journal of Environmental Management, 124, 82-90.

Bauer, T., \& Strauss, P. (2014). A rule-based image analysis approach for calculating residues and vegetation cover under field conditions. Catena, 113, 363-369.

Cao, S. (2010). Socioeconomic road in ecological restoration in China. Environmental Science \& Technology, 44, 5328-5329.

Cao, S. (2011). Impact of China's large-scale ecological restoration program on the environment and society in arid and semiarid areas of China: achievements, problems, synthesis, and applications. Critical Reviews in Environmental Science and Technology, 41, 317-335.

Cao, S., Chen, L., Shankman, D., Wang, C., Wang, X., \& Zhang, H. (2011). Excessive reliance on afforestation in China's arid and semi-arid regions: lessons in ecological restoration. Earth-Science Reviews, 104, 240-245. 
Cao, S., Zhang, J., Chen, L., \& Zhao, T. (2016). Ecosystem water imbalances created during ecological restoration by afforestation in China, and lessons for other developing countries. Journal of Environmental Management, 183, 843-849.

Chauhan, S., \& Ganguly, A. (2011). Standardizing rehabilitation protocol using vegetation cover for bauxite waste (red mud) in eastern India. Ecological Engineering, 37, 504-510.

Comiti, F., Da Canal, M., Surian, N., Mao, L., Picco, L., \& Lenzi, M. A. (2011). Channel adjustments and vegetation cover dynamics in a large gravel bed river over the last 200 years. Geomorphology, 125, 147-159.

Dubovyk, O., Menz, G., Conrad, C., Thonfeld, F., \& Khamzina, A. (2013). Object-based identification of vegetation cover decline in irrigated agro-ecosystems in Uzbekistan. Quaternary International, 311, 163-174.

Eckert, S., \& Engesser, M. (2013). Assessing vegetation cover and biomass in restored erosion areas in Iceland using SPOT satellite data. Applied Geography, 40, 179-190.

Gao, Y., Zhong, B., Yue, H., Wu, B., \& Cao, S. (2011). A degradation threshold for irreversible loss of soil productivity: a long-term case study in China. Journal of Applied Ecology, 48(5), 1145-1154.

Goirán, S.B., Aranibar, J.N., \& Gomez, M.L. (2012). Heterogeneous spatial distribution of traditional livestock settlements and their effects on vegetation cover in arid groundwater coupled ecosystems in the Monte Desert (Argentina). Journal of Arid Environments, 87, 188-197.

Ivits, E., Cherlet, M., Mehl, W., \& Sommer, S. (2009). Estimating the ecological status and change of riparian zones in Andalusia assessed by multi-temporal AVHHR datasets. Ecological Indicators, 9(3), 422-431.

Jiapaer, G., Chen, X., \& Bao, A. (2011). A comparison of methods for estimating fractional vegetation cover in arid regions. Agricultural and Forest Meteorology, 151(12), 1698-1710.

Jing, X., Yao, W. Q., Wang, J. H., \& Song, X. Y. (2011). A study on the relationship between dynamic change of vegetation coverage and precipitation in Beijing's mountainous areas during the last 20 years. Mathematical and Computer Modelling, 54(34), 1079-1085.

Jönsson and Eklundh. (2002). Seasonality extraction by function fitting to time-series of satellite sensor data. IEEE Transactions on Geoscience and Remote Sensing, 40(8), 1824-1832.

Kong, D., Miao, C., Borthwick, A. G. L., Duan, Q., Liu, H., Sun, Q., et al. (2015). Evolution of the Yellow River Delta and its relationship with runoff and sediment load from 1983 to 2011. Journal of Hydrology, 520, 157-167.

Kyle, G., \& Duncan, D.H. (2012). Arresting the rate of land clearing: change in woody native vegetation cover in a changing agricultural landscape. Landscape and Urban Planning, 106, 165-173.

Lan, J. C., Sun, Y. C., Xiao, S. Z., \& Yuan, D. X. (2016). Polycyclic aromatic hydrocarbon contamination in a highly vulnerable underground river system in Chongqing, Southwest China. Journal of Geochemical Exploration, $168,65-71$.

Lanfredi, M., Simoniello, T., \& Macchiato, M. (2004). Temporal persistence in vegetation cover changes observed from satellite: development of an estimation procedure in the test site of the Mediterranean Italy. Remote Sensing of Environment, 93, $565-576$.

Li, X., Zhou, W., \& Ouyang, Z. (2013). Forty years of urban expansion in Beijing: what is the relative importance of physical, socioeconomic, and neighborhood factors? Applied Geography, 38, 1-10.

Miao, C., Kong, D., Wu, J., \& Duan, Q. (2016a). Functional degradation of the water-sediment regulation scheme in the lower Yellow River: spatial and temporal analyses. Science of the Total Environment, 551, 16-22.

Miao, C., Sun, Q., Borthwick, A. G. L., Duan, Q. (2016b). Linkage between hourly precipitation events and atmospheric temperature changes over China during the warm season. Scientific Reports 6 (art. 22543).

Okin, G. S. (2007). Relative spectral mixture analysis-a multitemporal index of total vegetation cover. Remote Sensing of Environment, 106, 467-479.

Okin, G. S., Clarke, K. D., \& Lewis, M. M. (2013). Comparison of methods for estimation of absolute vegetation and soil fractional cover using MODIS normalized BRDF-adjusted reflectance data. Remote Sensing of Environment, 130, 266-279.

Omuto, C. T., Vargas, R. R., Alim, M. S., \& Paron, P. (2010). Mixed-effects modelling of time series NDVI-rainfall relationship for detecting human-induced loss of vegetation cover in drylands. Journal of Arid Environments, 74, 1552-1563.

Ouyang, W., Hao, F., Skidmore, A. K., \& Toxopeus, A. G. (2010). Soil erosion and sediment yield and their relationships with vegetation cover in upper stream of the Yellow River. Science of the Total Environment, 409(2), 396-403.

Pulido-Fernández, M., Schnabel, S., Lavado-Contador, J. F., Miralles Mellado, I., \& Ortega Pérez, R. (2013). Soil organic matter of Iberian open woodland rangelands as influenced by vegetation cover and land management. Catena, 109, 13-24.

Qu, J., Cao, S., Li, G., Niu, Q., \& Feng, Q. (2014). Conservation of natural and cultural heritage in Dunhuang, China. Gondwana Research, 26, 1216-1221.

Setiawan, Y., Yoshino, K., \& Prasetyo, L. B. (2014). Characterizing the dynamics change of vegetation cover on tropical forestlands using multi-temporal MODIS EVI. International Journal of Applied Earth Observation and Geoinformation, 26, 132-144.

Soepboer, W., Sugita, S., \& Lotter, A. F. (2010). Regional vegetation-cover changes on the Swiss Plateau during the past two millennia: a pollen-based reconstruction using the REVEALS model. Quaternary Science Reviews, 29, 472-483.

Turrion, M. B., Lopez, O., Lafuente, F., Mulas, R., Ruiperez, C., \& Puyo, A. (2007). Soil phosphorus forms as quality indicators of soils under different vegetation covers. Science of the Total Environment, 378, 195-198.

Wilson, J. W., Sexton, J. O., Todd Jobe, R., \& Haddad, N. M. (2013). The relative contribution of terrain, land cover, and vegetation structure indices to species distribution models. Biological Conservation, 164, 170-176.

Wing, B. M., Ritchie, M. W., Boston, K., Cohen, W. B., Gitelman, A., \& Olsen, M. J. (2012). Prediction of understory vegetation cover with airborne lidar in an interior ponderosa pine forest. Remote Sensing of Environment, 124, 730-741.

Wu, C. J., Tuo, J. C., Zhang, M. F., Sun, L. N., Qian, Y., \& Liu, Y. (2016). Sedimentary and residual gas geochemical characteristics of the Lower Cambrian organic-rich shales in Southeastern Chongqing, China. Marine and Petroleum Geology, 75, 140-150.

Xiao, Y., Xiao, Q., Ouyang, Z., Qin, M. (2015). Assessing changes in water flow regulation in Chongqing region, China. Environmental Monitoring and Assessment, 187 (art. 362). 
Zhang, J., Zhengjun, L., \& Xiaoxia, S. (2009). Changing landscape in the Three Gorges Reservoir Area of Yangtze River from 1977 to 2005: land use/land cover, vegetation cover changes estimated using multi-source satellite data. International Journal of Applied Earth Observation and Geoinformation, 11(6), 403-412.
Zhang, J., Zhao, T., Jiang, C., \& Cao, S. (2016). Opportunity cost of water allocation to afforestation rather than conservation of natural vegetation in China. Land Use Policy, 50, 67-73.

Zhou, H., Rompaey, A. V., \& Wang, J. A. (2009). Detecting the impact of the "Grain for Green" program on the mean annual vegetation cover in the Shaanxi Province, China using SPOTVGT NDVI data. Land Use Policy, 26, 954-960. 